\title{
Influence of a three weeks exposure to air pollution on lung function of elite wheelchair athletes
}

\author{
Perret $\mathbf{C}^{1,2 *}$, Leuppi $\mathbf{J}^{3}$, Michel $\mathrm{F}^{2}$ and Strupler $\mathbf{M}^{1,2}$ \\ ${ }^{1}$ Institute of Sports Medicine, Nottwil, Switzerland \\ ${ }^{2}$ Swiss Paraplegic Centre, Nottwil, Switzerland \\ ${ }^{3}$ Department for Internal Medicine, University Hospital Basel, Switzerland
}

\begin{abstract}
Objective: To assess possible effects of an expected three weeks air pollution on lung function of Swiss wheelchair athletes at the Paralympic Games 2008 in Beijing. Subjects: Thirteen wheelchair athletes (whereof 4 medically treated asthmatics) were included.

Methods: Forced vital capacity, forced expiratory volume in 1 s and peak expiratory flow was determined during the medical examination at home (pre-test) as well as during the first (post-test 1) and the third week (post-test 2) after the arrival at the Paralympic Village. Concomitantly concentration of particulate matters (PM10) was measured during the whole duration of the stay at the Paralympic Village.

Results: Post-test lung function measurements where performed $4.1 \pm 1.6$ days and $16.7 \pm 0.5$ days after arrival at the Paralympic Village. Analysis of variance revealed no differences concerning pre- and post-test lung function measurements. Average daily concentration of PM10 ranged between 22 and $119 \mu \mathrm{g} / \mathrm{m} 3$. No significant correlations were found between PM10 concentrations and lung function measurements.

Conclusion: Although quite high at some days, air pollution was less than suspected in advance of the Paralympic Games 2008 presumably due to restrictive sanctions (reduced traffic, closing down of factories) of the organising committee. The measured PM10 concentrations seemed to have no effect on lung function as none of the athletes showed any respiratory complications or decreased lung function during the stay at the Paralympic Village.
\end{abstract}

\section{Introduction}

Beijing is among the most air polluted megacities in the world. Based on this fact, many experts warned of decreased athletic performance and serious health problems in view of the Olympic and Paralympic Games 2008 [1]. Amongst other health problems, difficulties in breathing, respiratory discomfort, airway irritation, asthma like symptoms and a reduced forced expiratory volume in one second (FEV1) were expected to appear during the Olympic and Paralympic Games 2008 due to bad air quality [2].

Depending on lesion level, a spinal cord injury results in a severe reduction of lung function [3] and a restricted pulmonary capacity during physical activity [4]. Thus, compared to able-bodied athletes, wheelchair athletes seem to be even more prone to develop respiratory complications under bad air conditions, which possibly lead to a severe decrease in athletic performance. The aim of the present investigation was to assess possible effects of the expected air pollution on lung function of Swiss wheelchair athletes participating at the Paralympic Games 2008 in Beijing.

\section{Methods}

Subjects: Thirteen wheelchair athletes $(4 \mathrm{f} / 9 \mathrm{~m})$ from the Swiss National Paralympics Team 2008 participated in the study. Their average age was $37 \pm 10$ years, height $172 \pm 9 \mathrm{~cm}$ and weight $62 \pm 13$ $\mathrm{kg}$. Four of the athletes were known asthmatics and were medically treated (according to the World Anti-Doping Agency/Therapeutic Use Exemption guidelines) before as well as during the Paralympic Games. The study was approved by the ethics committee of Canton Lucerne,
Switzerland and all subjects gave their written informed consent before the start of the study.

Measurements: In order to detect possible changes in lung function parameters forced vital capacity (FVC), FEV1 and peak expiratory flow (PEF) were determined by means of a hand-held spirometer (MicroLab, Micro Medical Ltd, Kent, UK) in athletes during the medical examination at home (pre-test) as well as during the first week (post-test 1) and third week (post-test 2) after arrival at the Paralympic Village in Beijing.

Concentration of particulate matters (PM10) was measured during the whole duration of the stay in the Paralympic Village by a commercially available analyser (Aerosol Spektrometer 1.107, Eco Analytics, Pratteln, Switzerland).

Data analysis: To compare pre- and post-test lung function data a one way analysis of variance (ANOVA) for repeated measures was performed. Spearman correlation coefficients were calculated for delta and absolute values to test the relationship between lung function

*Correspondence to: Claudio Perret, Institute of Sports Medicine, Swiss Paraplegic Centre, CH-6207 Nottwil, Switzerland, Tel: +41 41939 6621; Fax: +41 41939 6601; E-mail: claudio.perret@paraplegie.ch

Key words: respiration, exercise, spinal cord injury, wheelchair racing, air pollution Received: August 13, 2018; Accepted: August 24, 2018; Published: August 27, 2018 
measurements and corresponding average daily PM10 concentrations. Statistical significance was set at $\mathrm{p}<0.05$.

\section{Results}

Post-test lung function measurements where performed $4.1 \pm 1.6$ days (post-test 1) and $16.7 \pm 0.5$ days (post-test 2) after arrival at the Paralympic Village. No significant differences concerning pre- and post-test measurements of FVC, FEV1 and PEF were found (Table 1) and none of the athletes complained about respiratory problems (e.g. dyspnea, cough) during the stay at the Paralympic Village.

Average daily concentration of PM10 ranged between 22 and $119 \mu \mathrm{g} / \mathrm{m} 3$ and exceeded the critical value of $50 \mu \mathrm{g} / \mathrm{m} 3$ defined by the government on most days (Figure 1). However, no significant correlations were found between PM10 concentrations and lung function measurements.

\section{Discussion}

Between 2000 and 2004 average annual PM10 concentrations in the urban areas of Beijing were reported to range between 141 and $166 \mu \mathrm{g} /$ $\mathrm{m} 3$ [5]. Although during some days quite high (PM10 concentration of up to $120 \mu \mathrm{g} / \mathrm{m} 3$ ), air quality during the Paralympic Games was much better (Figure 1) than expected based on the above reported data, presumably due to the restrictive sanctions (reduced traffic, closing down of factories) of the local organising committee. However, one has to be aware that the critical daily value $(50 \mu \mathrm{g} / \mathrm{m} 3)$ specified for Switzerland was clearly exceeded on most days (Figure 1).

Surprisingly, neither the four treated asthmatic nor the nonasthmatic athletes were complaining about respiratory problems during the three weeks stay in the Paralympic Village and it can be concluded that neither lung function (Table 1) nor athletic performance seems to

Table 1. Mean ( \pm standard deviation) forced vital capacity (FVC), forced expiratory volume in one second (FEV1) and peak expiratory flow (PEF) of 13 wheelchair athletes at home (pre-test) and during the first (post-test 1) and the third week (post-test 2) at the Paralympic Village

\begin{tabular}{|c|c|c|c|}
\hline Parameter & Pre-test & Post-test 1 & Post-test 2 \\
\hline FVC [L] & $4.24 \pm 1.05$ & $4.10 \pm 1.05$ & $4.03 \pm 1.04$ \\
\hline FEV1 [L] & $3.64 \pm 0.91$ & $3.48 \pm 0.88$ & $3.44 \pm 0.85$ \\
\hline PEF [L/s] & $8.61 \pm 3.04$ & $8.13 \pm 2.38$ & $8.25 \pm 2.64$ \\
\hline
\end{tabular}

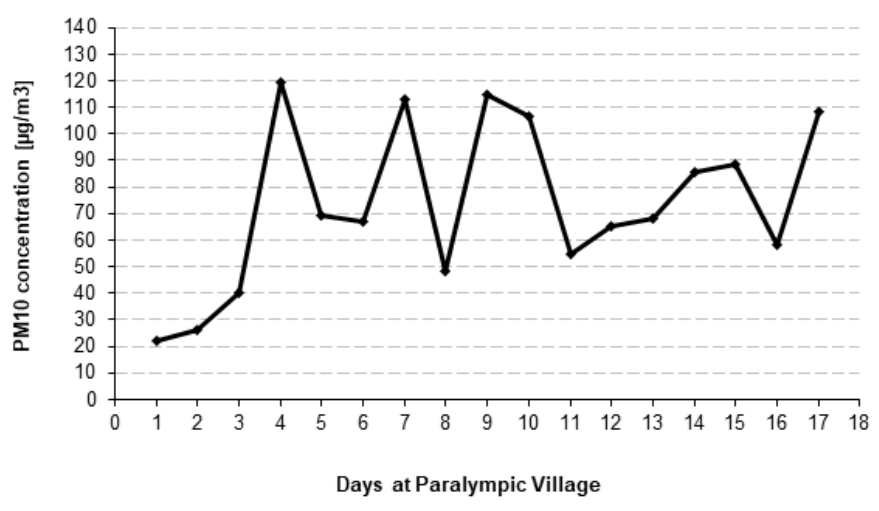

Figure 1. Average daily PM10 concentrations during the stay at the Paralympic Village. Note that the critical daily value of $50 \mu \mathrm{g} / \mathrm{m}^{3}$ was exceeded on most days

be negatively influenced due to PM10 concentrations of up to $120 \mu \mathrm{g} /$ $\mathrm{m} 3$ in spinal cord injured athletes. This assumption is supported by the fact, that many athletes reached seasonal or personal best results during their Paralympic competitions, although air quality was not excellent.

\section{Conclusion}

Bad air conditions with PM10 concentrations of up to $120 \mu \mathrm{g} / \mathrm{m} 3$ over a 3-week period seem to have no negative effects on lung function or respiratory complications in elite wheelchair athletes.

\section{References}

1. Lippi G, Guidi GC, Maffulli N (2008) Air pollution and sports performance in Beijing. Int J Sports Med 29: 696-698. [Crossref]

2. Florida-James G, Donaldson K, Stone V (2004) Athens 2004: the pollution climate and athletic performance. J Sports Sci 22: 967-980. [Crossref]

3. Kelley A, Garshick E, Gross ER, Lieberman SL, Tun CG, et al. (2003) Spirometry testing standards in spinal cord injury. Chest 123: 725-730. [Crossref]

4. Silva AC, Neder JA, Chiurciu MV, Pasqualin DC, da Silva RC, et al. (1998) Effect of aerobic training on ventilatory muscle endurance of spinal cord injured men. Spinal Cord 36: 240-245. [Crossref]

5. Zhang M, Song Y, Cai X (2007) A health-based assessment of particulate air pollution in urban areas of Beijing in 2000-2004. Sci Total Environ 376: 100-108. [Crossref]

Copyright: (C2018 Perret C. This is an open-access article distributed under the terms of the Creative Commons Attribution License, which permits unrestricted use, distribution, and reproduction in any medium, provided the original author and source are credited. 